\title{
L'Aquila, Central Italy, April 6, 2009: a Further Lesson to Civil Engineers
}

\author{
F. Casciati*, ${ }^{1}$ and A.L. Marcellini ${ }^{2}$ \\ ${ }^{1}$ Department of Structural Mechanics, University of Pavia, Pavia, Italy; ${ }^{2}$ Institute of Environmental Dynamic Processes, \\ National Research Center (CNR), Milan, Italy
}

\begin{abstract}
Earthquake engineering becomes a media issue for the four/six weeks which follow a catastrophic event. These periods of interaction between the societal actors and the topic experts is fruitful in terms of understanding how the scientists should arrange a state of the art. In particular, after the Central Italy event of April 6, 2009, among others, the following items arose: how coarse has to be the seismic hazard analysis? which is the role of microzonation? which is the preferable nature of the structural codes? are existing buildings exempt from retrofit duties? how the interactions in a urban nucleus should be managed? A further topic which belongs to the management of earthquake events rather than to earthquake engineering is seen to play a dominant role in the discussion: should the building owners be obliged to subscribe an insurance? This manuscript does not (and cannot) provide definite answers, but offers a witness of this interaction with the media within the context of a technical journal.
\end{abstract}

\section{INTRODUCTION}

The seismic event which occurred on April 6, 2009, in L'Aquila, Abruzzo, Central Italy, was the first earthquake with significant damage after the event which caused the failure of the school in San Giuliano in 2001. Soon after the event the National Institute of Geophysics and Volcanology (INGV), established in 1999, was charged by the National Civil Protection to undertake the investigations to assess a new seismic hazard map of the Italian territory with the aim to issue a new zonation map. This new arrangement also gave the same National Civil Protection Department (directly dependent on the Prime Minister) the authority to produce "ordinances", i.e., rules of immediate adoption supposed to be of transient validity up to the update of the necessary prescriptions by the competent authorities (ministries).

Nevertheless, the L'Aquila sequence of events did not only offer a verification of the preparedness of the country, of the ability of designers and constructors and of their ethical approach to the profession. It also gave rise to a list of new issues with i) unexpected PGA values larger than $0.6 \mathrm{~g}$ for a $\mathrm{M}_{\mathrm{L}}=5.8$ earthquake ii) public buildings, as hospital, government house and student college, which failed, iii) existing buildings which were inspected but not retrofitted, iv) buildings failing because the surrounding buildings were falling on them, v) retrofitted buildings failing because the retrofit was not ameliorative but was reducing the ability of the structure to survive the earthquake.

The contribution to this special issue offered the authors the possibility to record of their remarks.

\section{SEISMIC HAZARD ASPECTS}

Italy has a long record of catastrophic earthquakes. Heavy damages are often reported even in case of moderate

*Address correspondence to this author at the Department of Structural Mechanics, University of Pavia, Pavia, Italy;

E-mail: fabio@dipmec.unipv.it earthquakes. The recent April 6 Abruzzo earthquake, with some 300 casualties and the entire core of town of L'Aquila ruined, is not an exception in Italy. The core of the towns (and not only the core!) are mainly an assemblage of old houses and buildings that represent a valuable cultural heritage. Unfortunately they are not earthquake proof. A short summary of the last relevant Italian earthquakes could help to understand the evolution of the attitudes of Italian government and population with respect to earthquakes.

The 1908 Messina earthquake, when several towns collapsed, caused more than 80000 casualties. It has been probably the strongest Italian earthquake. The rescue organization was chaotic, but the Italian government, under the premier Giolitti, issued a series of decrees and laws to guide the reconstruction, with recommendations for retrofit, for the identification of safe zones (exclusion of marshy zones, landslide areas, etc.). In 1927 the government issued seismic regulations to be applied in the seismic zones: there was not a clear criterion to define the seismic zones, classified in category I or II. Basically an area previously struck by a damaging earthquake was included into the seismic zones.

On January 14, 1968, The Western part of Sicily was struck by a magnitude 5.5 earthquake. Several villages were destroyed mainly because of the bad quality of construction. On 1974 a seismic law has been issued, but Italy had to wait two strong earthquakes, the Friuli 1976 and the CampaniaBasilicata 1980, for a first seismic hazard map of the Italian territory. It was the results of the ad hoc project issued by the National Research Council (Progetto Finalizzato Geodinamica). Detailed investigations were performed to prepare a new earthquake catalog and new seismic zones. Seismic hazard has been assessed in terms of peak ground acceleration (PGA) and Macro-seismic Intensity for different return period, using the well-known Cornell approach. (Hazard Working Group, 1979) [1]. These first maps were eventually ameliorated after the improvement of the database as well as the adoption of computing methods. (Slejko,D et al, 1998) [2]. 
Also the seismic classification underwent several modifications. Before the 1980 Campania-Basilicata event, the Italian territory was subdivided into 3 zones (category I, category II and non seismic areas) with design PGA of $0.07 \mathrm{~g}$ and $0.1 \mathrm{~g}$ for the II and I category, respectively. After the 1980 earthquake, on the bases of the above mentioned hazard maps a new classification was issued by introducing a III seismic zone with PGA=0.04 (Servizio Sismico,1986) [3], (Gruppo di Lavoro,1999) [4].

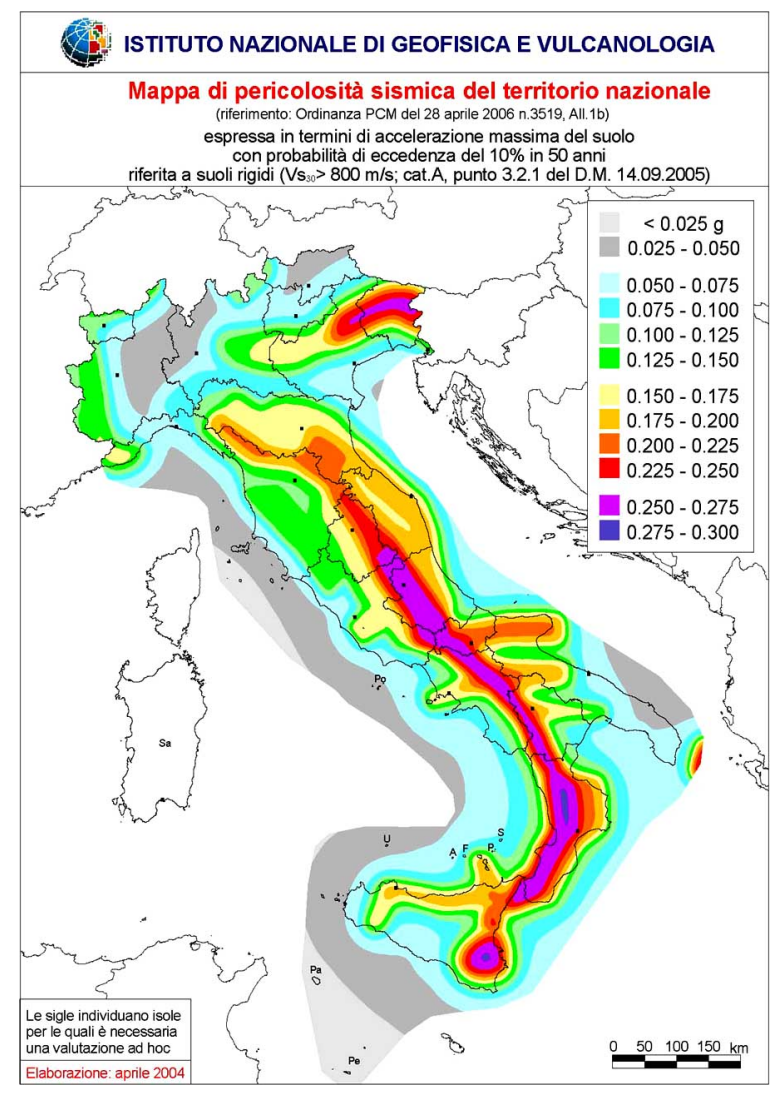

Fig. (1). Hazard map of Italy for 474 years return period ( Meletti et al.2007) [17].

A new revision of the hazard maps has been performed by INGV following the San Giuliano 2001 earthquake. Several hazard maps were issued: Fig. (1) reports the PGA map for 474 years of return period ( Meletti et al., 2007) [5] (Stucchi et al., 2003) [6].

It is worth noticing that the present hazard maps do not differ significantly from the 1979 maps as far as the identification of most seismic area is concerned. On the contrary the hazard values have been changed. It can be argued that a high reliability is achieved within Fig. (1).

\section{L'AQUILA EVENT}

In Fig. (1), L'Aquila, a town of less than 100000 inhabitants, is the dot at the Northern beginning of the more hazardous area spanning from Central Italy down to Sicily. According to INGV [7] the 6 April earthquake was assigned a $\mathrm{M}_{\mathrm{L}}=5.8$ and a $\mathrm{M}_{\mathrm{w}}=6.3$; the epicenter, as shown in Fig. (2), was located at some $6 \mathrm{~km}$ away from the town, with a prevailing direct fault mechanism. A phase cycle of the inter- ferogram corresponds to $2.8 \mathrm{~cm}$. That is, from figure 2 is possible to argue an overall displacement of more than 25 $\mathrm{cm}$. (of course the displacement is due to all the events till 14 April). Impressive were the PGA recorded that reached $0.645 \mathrm{~g}$ at the AQV station, located at a few $\mathrm{km}$ from L'Aquila on soil EUROCODE classed B (Ameri G. et al 2009) [8].

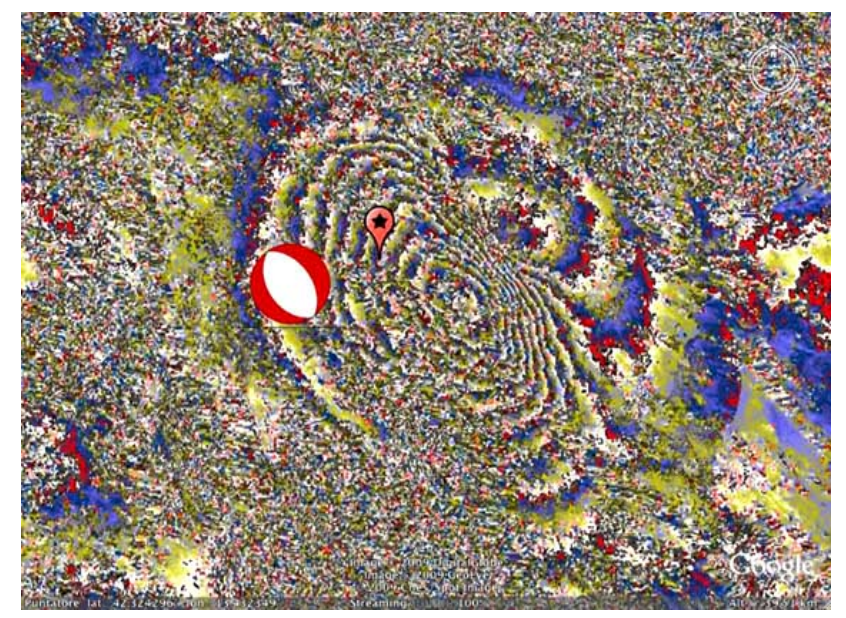

Fig. (2). ENVISAT interferogram geocoded between the acquisition of 1 February 2009 and 14 April 2009 , by descending orbits. The figure also shows the focal mechanism of the mainshock and the location of the town of L'Aquila (Courtesy IREA-CNR) [9].

The media reported these main features immediately after the event:

a) the hospital was declared unavailable;

b) the palace hosting the Prefecture (i.e., the national government house) failed;

c) a university college failed;

d) "gross errors" in design/construction of failed buildings have to be emphasized;

e) several monuments (mainly churches) showed irreversible damage;

f) entire villages around the town were completely destroyed;

g) many retrofitted buildings suffered damage;

h) a wide urban area became unavailable, due to the surrounding ruins.

The same media later collected and reported further bits of information, which are here organized in six items:

1) the buildings in the region of L'Aquila were deeply inspected in the Nineties by teams of technical experts; the consequent database was made available to the local politic authority;

2) a new national structural code was available, but its validity has been recently postponed to the summer of 2010 (June 30) (its validity was later anticipated to October 30, 2009);

3) the national Civil Protection is in charge of the alert and of the first rescue, but any amelioration of build- 
ings or infrastructures pursued in the absence of any previous catastrophic event is left to the local authority which usually can rely on resources very limited by budget constraints;

4) the rescue action of the national Civil Protection is demanded to its own personnel, putting in the corner the local professionals and technicians, who are supposed to possess a better understanding of the local conditions; also, in some cases, decisions are reached in partial conflict or in contrast with the wishes of the political local authority;

5) more than $50 \%$ of the buildings could have been reoccupied immediately by the occupants, but the water, power and gas networks resulted damaged;

6) new technologies, if correctly applied, could have prevented several buildings from failure.

In view of the discussion of the next sections, one further remark is essential. The emergency situation, managed under the strong psychological impact of a not-yet ended series of after-shocks, was suggesting the authority and the media a profile re-assuring the inhabitants of the devastated area. So official speakers were declaring that such an existing situation was "fully safe" or that a retrofit following some prescriptions would have been "fully safe".

Despite the emergency could justify such an approach, the lack of training of the population is evident. In Japan or in California, the inhabitants are educated to spend their life with a seismic risk. Mainly they know that the level of prevention the authority can introduce is the result of a cost benefit analysis, where the fully safe condition will never be reached. This remark, among others, motivated the discussion between the authors which has been recorded in this paper.

\section{STRUCTURAL CODES}

As previously mentioned the Italian seismic law dates 1974: basically it establishes the criteria for the zonation, for the seismic codes, for urban planning in seismic zones. In particular this last issue is under the authority of local administrations (the Regions). Structural codes were initially of competence of the Ministry of Public Works, later renamed the Ministry of Infrastructures, which is supposed to provide periodic updates. To fix a starting point in the series, the Order in Council of 1996 is suitable. Its nature (Ministry Decree) says that in Italy the Structural Codes are a law of the state, which come with explicative Circulars. In these circulars the details which cannot be explicitly put in a law format are collected and publicized. The 1996 document adopted the semi-probabilistic format (the so called LoadResistance-Factor-Design (LRFD) format) (Ellingwood et al., 1980) [10] (Augusti et al., 1984) [11] and the limit state design procedure, but also preserved the classical allowable stress method. It works in a fully prescriptive scheme, i.e., the designer is obliged to respect the prescription and this, in the case of unsuccessful design, will adjust his/her legal position.

After 1996, seismic events occurred in Umbria (1997) and in Sicily, but it was the failure of the school in Molise (2001) which was suggesting an update. In the absence of actions from the competent ministry, the Civil Protection Department produced an ordinance (OPCM 3274, 2003) [12], which was soon followed by a series of them (OPCM 3333,3451 and 3519). They were intended to cover the delay of the update expected from the Ministry of the Infrastructures, delay mainly due to the temporary coincidence with the incoming adoption, at a European level, of the Eurocodes.

The legislative framework was also modified: the Ministry of Internal Affairs (on which the firemen organization depends) is asked to sign in concert the structural codes by the Decree of the Republic President of June 6, 2001, n. 380; then also the Chief of the Civil Protection Department is asked to sign them in concert by the law July 17, 2004, n. 186.

The expected update of the structural codes from the Ministry of Infrastructures, with the agreement of the other two authorities, was published in 2005 (DM 2005, 2005) [13] which was conceived in a performance-based design format: the designer is free in his/her design choices, but will be responsible of any misbehavior of the designed structure. Such a document was subjected to a period of experimentation which was concluded into the new text (DM 2008, 2008) [14], again of a prescriptive nature. The latter document is the one mentioned in item 2 of the "L'Aquila Event" section. The explicative circular was made available at the beginning of 2009 and this suggested to make it operative by the summer of 2010. DM 2008 is ready for the adoption of the Eurocodes, which the European authority CEN want to see operative across Europe by 2010.

The DM 2005 [13] introduced a chapter on existing buildings. During its drafting, it became evident that structural codes only apply to new buildings. When an existing building is retrofitted from a structural point of view, then, in this case and only in this case the current structural codes have to be fulfilled. In other words, the owners of the great majority of buildings across Italy (most of them having been built in the two decades after the end of World War II) have no obligation toward special safety requirements. The discussion on this topic led the members of the committee in charge of the text redaction to consider at least the obligation for the owner of updating a file covering the building maintenance, as recently it was deliberated in France, but the solution was eventually discarded.

DM 2008 also comes with a description of the seismic hazard in terms of PGA defined by a dense array of nodes across the country. The zonation map issued after the Campania-Basilicata 1980 earthquake was significantly different from previous zonation. After that it evolved continuously and the actual zonation, shown in Fig. 3 (Civil Protection Department, 2006) [15], subdivides the Italian territory into 4 zones.

With respect to previous zonation proposals, it should be emphasized that the whole territory belongs to a seismic zone. All the previous non seismic areas were included into the Category IV zone. The National seismic code prescribes design spectra whose severity depends on the seismic category, namely, PGA $=0.05 \mathrm{~g}, 0.15 \mathrm{~g}, 0.25 \mathrm{~g}, 0.35 \mathrm{~g}$ for categories IV, III, II and I, respectively. These PGA values were 
assigned on the bases of the 474 years return period hazard map. Moreover, the design spectra are site dependent: The horizontal design spectra can be multiplied by factor ranging from 1 to 1.35 according to the mechanical properties of soil. Soils properties change also the spectral shape (the looser the soil the larger the plateau of the relevant periods). In conclusion one can say that as far as hazard and seismic classification is concerned, there are not important deficiencies. The scientific level of hazard maps, the procedure adopted for the seismic classification are very similar to the ones used in other Western countries like US, France, Greece and Japan. It is possible to see from Figs. (1) and (3) that L'Aquila was correctly individuated as a zone of elevated seismicity.

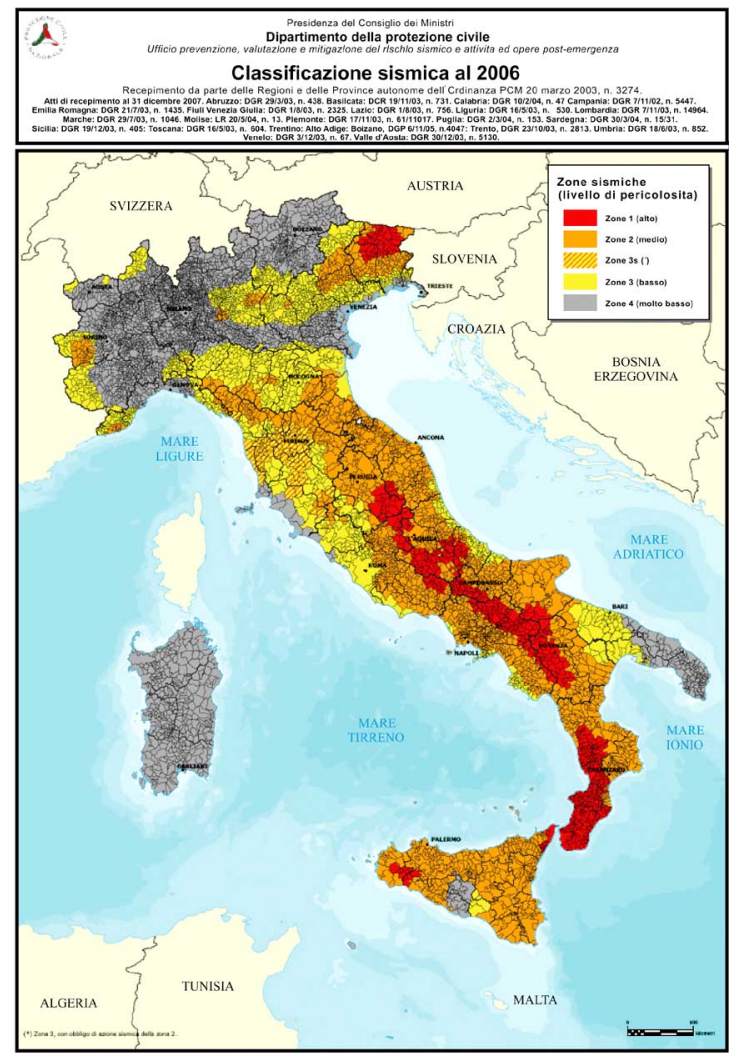

Fig. (3). Seismic zonation of Italy (Dipartimento della protezioneCivile,2006) [15] http://www.protezionecivile.it/cms/attach/editor/

But probably, considering the typologies of the Italian buildings and houses (not to talk of monuments!) also at the light of L'Aquila earthquake, something else must be done also in the hazard evaluation. In particular it seems that microzonation studies are necessary. This aspect will be further discussed in the section devoted to the Promising Developments .

\section{RESEARCH CONTRIBUTIONS}

The inspection campaign (reported as item 1 in the "L'Aquila Event" section) was the result of a great joint effort of the state authority and the academic word. For that purpose, the collection of data on existing buildings was also classified in the Nineties as a "socially useful activity", providing part time occupation to a significant amount of engineers and architect who at that time represented, in Italy, a large percent of unemployed people. The bases of the vulnerability classification can be found in (Casciati-Faravelli, 1991) [16] or in (Casciati et al., 1994), [17] among others. The results were collected in academic master theses (Picciocchi, 1998) [18], as well as in informatics databases. When entering http://dipmec.unipv.it/, the user was also addressed at that time to areas of restricted access, but he/she was asked a password to login this database. This was the result of a long discussion on the psychological potential of a public availability of data on the quality of the buildings on the occupants. Unfortunately, these databases were left with no subsequent action (of retrofit) mainly because of the limited economic resources available to the responsible local authorities. The scientists tried to work on the real world, but their effort was fruitless!

Efforts were also conducted toward the formulation of numerical models of simulation, as it is done in many applied sciences. The Polish mathematician B. Mandelbrot is mainly famous for his works on the fractal geometry but he also wrote, recently, a book (Mandelbrot, 2004) [19] giving an alert to people too confident in numerical models. In a period in which all Economics is shaken by the inadequate use of predictive mathematical models of the market evolution, Mandelbrot explains that the problems do not come from formulae, but from the kind of Mathematics one adopts. When there is a basic assumption of "smooth variability", sudden failure cannot be foreseen. They are regarded as anomalies and marked as misbehaviors, but they represent the normal performance of the markets. When working with a mild randomness, the total risk are underestimated and this produce a false feeling of safety. The conclusion the author reaches is that the markets behave in a much more complex way than the standard models show.

A similar reasoning applies to earthquake engineering, where in addition to "inadequate basic assumptions" one also plays with wrong boundary conditions and the ignorance of the in-homogeneities which characterize soils and structural materials. They could be neglected when assessing the structural performance under standard conditions, but become dominant in predicting the way to progressive failure under catastrophic events (Starossek, 2009) [20].

These remarks pushed the scientists toward experimental rather than numerical activities. It was easy to forget the availability of existing shaking table facilities (Casciati, 1998) [21] and to invest in the construction of new ones. Unfortunately, the Buckingham theorem prevents one from scaling systems with nonlinear behavior and this obliges to pursue full scale experiments: two testing centers are presently showing this features, one is in Japan and the other in San Diego, California. Smaller equipments are only useful to test structural components, provided one is able to set the suitable boundary conditions. The alternative approach based on "Pseudo-dynamics" (Casciati-Magonette, 1999) [22] seems to be abandoned despite its effectiveness.

Many experimental tests were supported at a European level but they did not produce a real breakthrough, except perhaps in the area of the conservation of the monumental heritage (Syrmakezis, 2008) [23]. By contrast, the Europe support was fundamental in the construction of world-wide accelerogram database (Ambraseys et al., 2004) [24], which 
opened the door to specific techniques for the construction of site specific acceleration time history samples (Casciati et al., 2001) [25] useful in both analytical and experimental studies.

\section{THE INSURANCE ISSUE}

Even in the presence of a real breakthrough coming from the research and its immediate implementation in the structural codes, the better quality of the new buildings will affect the consequences to the events which will occur decades from now. The current events have to play with the existing buildings and with the lack of any rule on their maintenance. Moreover, even if one invests money in the retrofitting of his/her building, the performance of that building is not independent of the one of the surrounding constructions.

The national Civil Protection budget is nearly 150 millions euro per year when no catastrophic event occurs: this means each Italian resident pay a little less than 3 euro per year. But the final budget of the seismic event occurred in Umbria in 1997 resulted of 11 billions of euro in 10 year, all provided by the central government. Here each citizen contributed with 100 euro per year! Therefore, after the L'Aquila event, the media reported many letters from citizens who denied further donation for the new catastrophe, since their contribution was already in the taxes they paid in the previous years.

Japan, US and France already introduced the obligation for the owners to ensure the buildings. An interview to the president Fabio Cerchiai of the insurance company association (ANIA) emphasized how the cost of insurance would be too elevated if spread over the buildings in the damaged area, but it would result of 100 euro per house (not per citizen) when the obligation would have covered all Italy (Corriere della Sera, April 20, 2009).

Associated with the insurance obligation, there is also the maintenance issue, since the owner of a well maintained building would pay a lower amount to the insurance company. Moreover, starting such an insurance business would originated a database of the buildings managed by the different insurance companies which would provide the owner awareness of the real conditions of its building.

Perhaps it would be undesired by the structural designers, but the insurance company will also exert that role of controller of the design and construction process which the local authorities showed to be unable to have (items 3 and 4 in the "L'Aquila Event" section; the insurance coverage would also help in avoiding item 5 , since it results in an increase of the prize to be paid from the insurance company to the building owner after the catastrophic event).

Just to clarify this aspect, consider Fig. (4), which is rearranged from a picture published in the newspaper Corriere della Sera of April 10, 2009. It comes with a text explaining which are the ameliorations (marked by disks) one can pursue on an old masonry house.

The same day the national broadcasting company interviewed a family which invested money in the retrofit of the house of property: but the top surrounding beam was not adequately fixed to the masonry walls, so that the shake resulted in a rotation of the roof as a rigid body on the under- standing masonry body of the building. A suitable control of the executed works would have avoided any problem. In the absence of a public authority devoted to this task, the insurance company technicians could usefully exert the role!

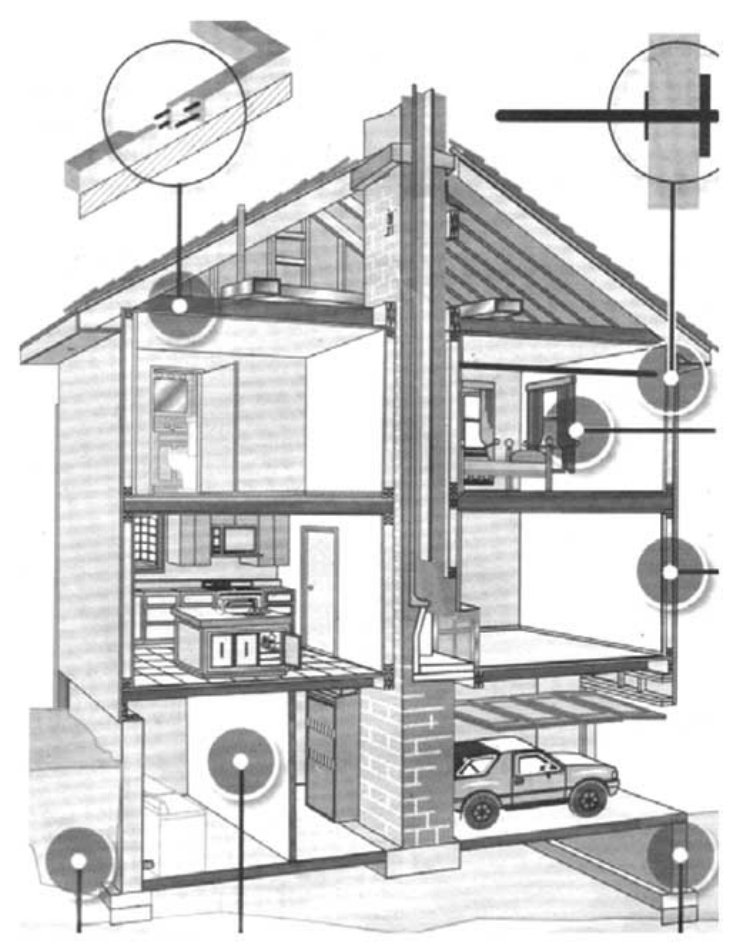

Fig. (4). Ameliorations for the retrofit of a masonry building (rearranged from Corriere della Sera, April 10, 2009).

Furthermore, the monitoring today restricted to strategic structures (Nicoletti et al., 2006) [26] could be extended to other buildings under the direction of a pool of insurance companies.

Of course, there is a party among the citizens against this obligation: it regards the insurance cost as an additional tax to be avoided.

\section{PROMISING DEVELOPMENTS}

Promising developments can be envisaged; they cover:

a) a good zonation map;

b) the adoption of innovative devices (Casciati et al., 2006) [27];

c) the selection of performance-based design procedures with the right weight given to the robustness issue (Faber, 2008) [28] (Starossek, 2009) [20].

Despite a good zonation map and an updated seismic code, 300 casualties were recorded and L'Aquila was destroyed for a magnitude 5.8 earthquake, that is a moderate earthquake. Undoubtedly something did not work correctly.

1) The hazard evaluation procedure is basically the Cornell approach, adopted worldwide and considered till now as the best method for the compilation of the official seismic zones, despite some dubious items, like the homogeneous Poisson process used to model earthquake occur- 
rence. Moreover empirical attenuation laws play important role in determining the final hazard figures. It seems that new procedures to compute seismic hazard must be introduced, in particular disaggregation techniques based on a full probabilistic approach (Pagani-Marcellini, 2007) [29] could help. In addition deterministic or stochastic approaches should be performed to assess design spectra. L'Aquila belongs to the category II zone, where on the basis of hazard a design PGA of $0.25 \mathrm{~g}$ has been assigned. Despite the low magnitude, the April-6 event, caused more than $0.6 \mathrm{~g}$ PGA. This value is by far larger than the 50 percentile of the 474 years RP map shown in Fig.1, denoting the inadequacy of the classical probabilistic approaches to assess design forces.

2) The role of site effects has been evidenced by a number of earthquakes worldwide and does not merit further explanations. A correct site effect evaluation cannot be done simply with the application of soil category as indicated in the seismic codes. Microzonation investigations are nowadays necessary to take properly into account both soil and source behavior (directivity of radiation, amplification factors, non-linear soil effects, liquefaction susceptibility, induced landslides etc.) (Marcellini \& Pagani,2004) [30]. Some Italian regions, like for example Emilia Romagna, are recommending microzonation investigations (Servizio Geologico, R. E.R., 2007) [31].

3) The first spectral re-elaborations from the acceleration record obtained at $4.8 \mathrm{~km}$ from the epicenter show spectral peaks at the period $0.1,0.15$ and $0.4 \mathrm{~s}$. which are much larger than those offered by the new structural code, whose prescriptive nature, however, prevents one from any criticism.

Within this framework, it will be certainly useful to retrofit existing buildings and/or to design the new ones by relying on the help of innovative devices as base isolators and dampers. Nevertheless, it must be well stated that the resulting constructions are not "fully safe". They will perform satisfactorily below a threshold which is used to design the devices. Higher this threshold is required, much higher will be the resulting cost of the construction. Since this threshold is mainly assessed on the basis of the hazard analysis results, the previously listed items must be all adequately considered.

Within a performance-based design framework the designer has to consider all the likely scenarios and to understand the structural system response for all of them. To avoid disproportionate consequences to insignificant initiating event is the target of structural robustness. Inside the structural systems, robustness can be ensured by the addition of ties, links, constraints which prevents from progressive collapse. A similar study of the structure inserted in an urban nucleus system is something that scientists should start to show as feasible.

\section{CONCLUSIONS}

The L'Aquila event of April 6, 2009, together with its long series of aftershocks, emphasized the need of disseminating at a capillary level the bases of Earthquake Engineering as reformulated decades ago in the US and Japan.
The concepts of living surrounded by risks and of assigning targets to risk mitigation consistent with the economic richness of the living people were not in the background of the population which suffered the event. There is a justification for this: L'Aquila was fully destroyed by an earthquake in the eighteenth century, but the gap between the two events is much longer than the family memory. This remark holds across all Italy.

Nevertheless, after the event occurred, it is pity to rely on the length of the gap to the next strong event for depicting as "fully safe" situations which are not so.

On the other side, any cost-benefit analysis would suggest to adopt low profile countermeasures, mainly to avoid that the costs of the reconstruction become unbearable.

Focus should be put on:

a) the adoption of suitable micro-zonation procedures;

b) structural codes no longer of a prescriptive nature but of the performance-based design class;

c) dominant role in the design of the robustness issues;

d) the study of the urban nucleus, rather than single isolated buildings;

e) an insurance obligation driving toward the suitable retrofit of existing buildings;

f) the dissemination of a culture where maintenance is a rule of life rather than a useless appendage.

\section{ACKNOWLEGMENTS}

This manuscript was made possible by the ongoing cooperation between the Graduate School of Civil Engineering at the University of Pavia and the IPDA, Milan, of the National Research Council.

\section{REFERENCES}

[1] Hazard Working Group, Preliminary hazard maps of the national territory (in Italian), C.N.R. P.F. Geodinamica. Publ 227, ESA, Roma, 25, pp. 1979.

[2] D. Slejko, L. Peruzza, and A. Rebez, "Seismic hazard maps of Italy", Annali di Geofisica, vol. 41, pp. 183-214, 1998.

[3] Seismic Bureau of the Great Council of the Public Works, Maps of the national seismic classification (in Italian), Ist. Poligrafico e Zecca dello Stato, Roma, p. 209, 1986.

[4] Working Group, "Proposal of seismic re-classification of the national territory" (in Italian), Ingegneria Sismica, vol. 14(1), pp. 5$14,1999$.

[5] C. Meletti, and V. Montaldo, "Seismic hazard estimations for different exceeding probability in 50 years: values of $\mathrm{a}_{\mathrm{g}}$ " (in Italian). Project DPC-INGV S1, Deliverable D2, 2007 http://esse1.mi.ingv.it/d2.html

[6] M. Stucchi, A. Akinci, A. Amato, L. Malagnini, C. Meletti, F. Meroni, G. Selvaggi, G. Valensise, and G. Zonno, Seismic hazard map (in Italian), OPCM 3274, all.1, Rapporto Finale,2003http://zonesis-miche.mi.ingv.it/documenti/preview_rapporto finale. pdf

[7] INGV The seismic sequence in the Aquila area - April 2009 http://portale.ingv.it/primo-piano/archivio-primo-piano/notizie-2009/terremoto-6-aprile/copy_of_la-sequenza-sismica-dell-aquilano-aprile2009/

[8] G. Ameri, P. Augliera, D. Bindi, E. D’Alema, C. Ladina, S. Lovati, L. Luzi, S. Marzorati, M. Massa, F. Pacor, and R. Puglia, Strongmotion parameters of the $\mathrm{MW}=6.3$ Abruzzo (CentralItaly) earthquake http://www.mi.ingv.it/docs/report_RAN_20090406.pdf

[9] CNR Abruzzo Earthquake: IREA Activity http://terremotoabruzzo.irpi.cnr.it/, 2009

[10] B. Ellingwood, T. V. Galambos, J. C. McGregor, and C. A. Cornell, "Development of a probability based load criterion for Ameri- 
can National Standard A58", NBS Special Publication 577, National Bureau of Standards: Washington, 1980.

[11] G. Augusti, A. Baratta, and F. Casciati, Probabilistic Methods in Structural Engineering, Chapman and Hall: London, 1984.

[12] Prime Ministry Ordinance (OPCM) 3274, Gazzetta Ufficiale 252 del 20-10-2003, 2003.

[13] Ministry Decree 14-09-2005 (in Italian), Gazzetta Ufficiale, 222, 23-09-2005, 2005

[14] Ministry Decree 14-01-2008 (in Italian), Gazzetta Ufficiale 29, 0402-2008, 2008.

[15] Civil Protection Department, Seismic classification 2006 (in Italian), 2006. http://www.protezionecivile.it/cms/-attach/editor

[16] F. Casciati, L. Faravelli, Fragility Analysis of Complex Structural Systems, Reasearch Studies Press: Taunton, UK, 1991.

[17] F. Casciati, L. Faravelli, and Liu X.D, "Lessons of rehabilitation design learned from statistical analyses of masonry sismicvulnerability data", Structural Safety, vol. 16(1-2), pp. 73-90, 1994.

[18] S. Picciocchi, "Seismic Vulnerability: Elaboration of the Italian Database", (in Italian), Master Thesis, University of Pavia, 1998.

[19] B. Mandelbrot, The (Mis) Behavior of Markets: A Fractal View of Risk, Ruin, and Rewards, Basic Books, 2004. (also: Il disordine dei mercati: una visione frattale di rischio, rovina e redditività (in Italian), Einaudi, Torino, Techno Press, 2005.

[20] U. Starossek, Progressive Collapse of Structures, Thomas Telford Publishing: London, UK, 2009.

[21] F. Casciati, "Scale laboratory testing towards actual actively controlled structural systems", Proceeding $2^{\text {nd }}$ Structural Control World Conference, John Wiley and Sons: Chichester, 1999.

[22] F. Casciati and G. Magonette, "Testing facilities and laboratory validation", J. Rodellar, A. H. Barbat and F. Casciati, Eds. Advances in Structural Control, CIMNE: Barcelona, Spain, 1999.
[23] N. N. Ambraseys, P. Smit, J. Douglas, B. Margaris, R. Sigbjörnsson, S. Ólafsson, P. Suhadolc, and G. Costa, CD-ROM European Strong-Motion Database, vol. 2, 2004.

[24] C. A. Syrmakezis, "WIND-CHIME special issue", Ed. Smart Structures and Systems, vol. 4(2), 2008.

[25] F. Casciati, S. Casciati, and A. Marcellini, "PGA and structural dynamics at a given site", Journal of Earthquake Engineering and Engineering Vibration, vol. 2 (1), pp. 25-34, 2003.

[26] M. Nicoletti, B. G. Lamonaca, and D. Spina, "The Italian network for seismic monitoring of structures: design, present level of realisation and further development". Proceedings of the Sixth European Conference on Structural Dynamics (EURODYN 2005), September 4-7, Paris, France, 2005.

[27] F. Casciati, G. Magonette, and F. Marazzi, Technology of Semiactive Devices and Applications in Vibration Mitigation, John Wiley \& Sons: Chichester, 2006.

[28] M. H. Faber, Proceedings of the 1st Workshop on Action TU0601, Ed. Robustness of Structures, ETH Zurich, 2008.

[29] M. Pagani, and A. Marcellini, "Seismic hazard disaggregation: a fully probabilistic methodology", Bulletin of Seismological Society of America (BSSA), vol. 97, pp. 1688-1701, October 2007.

[30] A. Marcellini, and E. M. Pagani, "Seismic zonation methodologies with particular reference to the italian situation", in A. Ansal, Ed. "Recent Advances in Earthquake Geotechnical Engineering and Microzonation", Kluwer Academic Publishers: Dordrecht, The Netherlands, 2004.

[31] Geologic, Seismic, and Soil Bureau, Region Emilia Romagna, "Guidelines for the studies of seismic micro-zonation in EmiliaRomagana for the territory and urban planning" (in Italian), 2007, http://www.regione.emilia romagna.it/wcm/geologia/canali/sismica/Microzonazione/Indirizzi.htm

(c) Casciati and Marcellini; Licensee Bentham Open.

This is an open access article licensed under the terms of the Creative Commons Attribution Non-Commercial License (http://creativecommons.org/licenses/by-nc/3.0/) which permits unrestricted, non-commercial use, distribution and reproduction in any medium, provided the work is properly cited. 